\title{
Pseudocowpox Virus
}

National Cancer Institute

\section{Source}

National Cancer Institute. Pseudocowpox Virus. NCI Thesaurus. Code C112401.

A species of viruses in the Poxviridae family and Parapoxvirus genus. Pseudocowpox

viruses are mainly found in cattle and cause mild sores on cow teats and udders.

Pseudocowpox viruses can also infect humans via direct contact with infected dairy cattle during the milking process, and cause the skin disease milker's nodule. 